\title{
Impacts of Light Rail Transit Tram on the Voltage and Unbalance of the Distribution System
}

\author{
Cheng-Ting Hsu, Hung-Ming Huang, Tsun-Jen Cheng, and Lian-Jou Tsai \\ Department of Electrical Engineering, Southern Taiwan University of Science and Technology, Tainan 710, Taiwan \\ Correspondence should be addressed to Tsun-Jen Cheng; chengtj@mail.stust.edu.tw
}

Received 10 September 2013; Accepted 4 October 2013

Academic Editor: Teen-Hang Meen

Copyright ( $) 2013$ Cheng-Ting Hsu et al. This is an open access article distributed under the Creative Commons Attribution License, which permits unrestricted use, distribution, and reproduction in any medium, provided the original work is properly cited.

This paper presents the three-phase voltage and unbalance analysis for the distribution system with the loading of a light rail transit (LRT) tram. To investigate the dynamic responses of the system voltage and current, this paper adopts the Alternative Transients Program (ATP) software to model and simulate a multigrounded four-wire distribution system with an LRT loading. Two different definitions about unbalance are used to evaluate the problem. In this paper, the traction supply substation (TSS) with a singlephase transformer configuration is designed first for providing the electric power to the trams of LRT. However, it may result in the significant neutral line current and unbalance phenomenon to deteriorate the power quality of the distribution system. A Le-Blanc connection transformer in the TSS is therefore proposed to solve the problems.

\section{Introduction}

Many counties and cities in the world are keen on planning light rail transit (LRT) system to meet the growing demand of public transportation. The LRT takes the advantages of low cost, low noise, low pollution, mature technology, short construction period, and easy maintenance. In addition, it may utilize electrical power from distribution systems of power grid because of its lower power requirements than the traditional railway and mass rapid transit systems. In general, it is very suitable to use the LRT as the public transport of the metropolitan areas and a variety of urban transport connections [1-3]. The tram of LRT is a heavy and irregular load, and it carries many power electronic equipment; the power quality of the distribution system can inevitably be affected $[4,5]$. For the distribution system with the LRT, it may cause voltage fluctuation, unbalance, and harmonic and other power quality issues. To ensure the power quality, utilities have published many limits on these issues.

The traction power substation (TSS) supplies the LRT with either alternating current (AC) or direct current (DC) electric power. Mostly, the AC power may cause three-phase unbalance problem, while the DC power supply will generate a harmonic problem. In this paper, the AC supply systems are considered, and the three-phase unbalance problem is the main investigation issue. This study case is based on a typical Taiwan Power Company (Taipower) $11.4 \mathrm{kV}$ distribution feeder with four-wire and multigrounded system [6]. And the ATP [7] software is applied to establish the selected distribution feeder and the different AC power supply structures of the LRT. After that, it is used to execute three different operating scenarios. The instantaneous threephase voltage and current and neutral line current are therefore simulated to calculate unbalance. By the way, two different definitions, the negative sequence unbalance ratio and unbalance factors [8], are both adopted for evaluating the three-phase unbalance of the distribution system.

\section{LRT Impacts on the Unbalance of the Distribution Systems}

Three-phase voltages $\left(V_{A}, V_{B}\right.$, and $\left.V_{C}\right)$ can be decomposed into three separate phase sequence $\left(V_{1}\right)$, the negative phase sequence $\left(V_{2}\right)$, and the zero-phase sequence $\left(V_{0}\right)$ components, as shown in (1). It is well known that only the positive 
phase sequence exists in the balanced system. Consider

$$
\left[\begin{array}{l}
V_{0} \\
V_{1} \\
V_{2}
\end{array}\right]=\frac{1}{3}\left[\begin{array}{ccc}
1 & 1 & 1 \\
1 & a & a^{2} \\
1 & a^{2} & a
\end{array}\right]\left[\begin{array}{l}
V_{A} \\
V_{B} \\
V_{C}
\end{array}\right],
$$

where $a=120 \angle 0^{\circ}$. Negative sequence unbalance in a three-phase system is defined as the ratio of the magnitude of the negative sequence component to the magnitude of the positive sequence component, while the zero sequence unbalance is defined as the magnitude of the zero sequence component to the magnitude of the positive sequence component, expressed as a percentage [8]. This definition can be applied for either voltage or current as shown in the following:

$$
\begin{aligned}
& d_{2}(\%)=\frac{V_{2}}{V_{1}} \times 100 \% \\
& d_{0}(\%)=\frac{V_{0}}{V_{1}} \times 100 \% \\
& m_{2}(\%)=\frac{I_{2}}{I_{1}} \times 100 \% \\
& m_{0}(\%)=\frac{I_{0}}{I_{1}} \times 100 \%
\end{aligned}
$$

In addition, three-phase voltage unbalance factor (VUF) and current unbalance factor (IUF) can also be defined as the ratio of the maximum deviation of a voltage or current from the average value to the average value, expressed in percentage, using phase-to-phase voltage or current as follows:

$$
\begin{aligned}
\operatorname{VUF}(\%)= & \frac{\operatorname{Max}\left(\left|V_{\mathrm{avg}}-V_{A B}\right|,\left|V_{\mathrm{avg}}-V_{B C}\right|,\left|V_{\mathrm{avg}}-V_{C A}\right|\right)}{V_{\mathrm{avg}}} \\
& \times 100 \%, \\
\operatorname{IUF}(\%)= & \frac{\operatorname{Max}\left(\left|I_{\mathrm{avg}}-I_{A B}\right|,\left|I_{\mathrm{avg}}-I_{B C}\right|,\left|I_{\mathrm{avg}}-I_{C A}\right|\right)}{I_{\mathrm{avg}}} \\
& \times 100 \%,
\end{aligned}
$$

where

$$
V_{\mathrm{avg}}=\frac{V_{A B}+V_{B C}+V_{C A}}{3}, \quad I_{\mathrm{avg}}=\frac{I_{A B}+I_{B C}+I_{C A}}{3} .
$$

The voltage and current unbalance ratio limitations are set with different provisions according to different types of load duration by different institutions. In general, the voltage service of negative sequence unbalance $\left(d_{2}\right)$ is less than $3 \%$. The current unbalance can be considerably higher, especially when single-phase loads are present [8]. For the rail systems in Taiwan, the value is limited to $1 \%$ and $1.2 \%$ for one day and 15 minute measurement period, respectively.

\section{Le-Blanc Connection Transformer}

A single-phase power supply for LRT will give rise to the problem of three-phase unbalance. In general, this problem can be improved by using the static var compensators (SVC) or a special connection of transformers, such as the LeBlanc transformer connection. The purpose of the Le-Blanc transformer connection is to convert a three-phase system into two single-phase systems with symmetrical primary current. Figure 1 shows the wiring diagram of the Le-Blanc transformer [9]. The secondary outputs of two single-phase voltages, $V_{m}$ and $V_{t}$, have the characteristics of equal magnitude and 90 degrees phase shift. $N_{1}$ and $N_{2}$ are the number of winding turns at primary and secondary, respectively. Figure 2 gives the voltage vector diagram of the transformer.

The relations of the primary and secondary voltages of the Le-Blanc transformer can be written as

$$
\begin{gathered}
V_{m}=\frac{1}{\sqrt{3}} \frac{N_{2}}{N_{1}}\left(V_{B}+V_{C}-2 V_{A}\right), \\
V_{t}=\frac{N_{2}}{N_{1}}\left(V_{B}-V_{C}\right) .
\end{gathered}
$$

The primary currents of the transformer are given by

$$
\begin{aligned}
& I_{A}=I_{A B}-I_{C A}, \\
& I_{B}=I_{B C}-I_{A B}, \\
& I_{C}=I_{C A}-I_{B C} .
\end{aligned}
$$

Also, the primary and secondary currents are dependent and can be expressed as

$$
\begin{gathered}
I_{C A}=\frac{1}{\sqrt{3}} \frac{N_{2}}{N_{1}} I_{m}-\frac{1}{3} \frac{N_{2}}{N_{1}} I_{t}, \\
I_{B C}=\frac{2}{3} \frac{N_{2}}{N_{1}} I_{t}, \\
I_{A B}=-\frac{1}{\sqrt{3}} \frac{N_{2}}{N_{1}} I_{m}-\frac{1}{3} \frac{N_{2}}{N_{1}} I_{t} .
\end{gathered}
$$

Substituting (7) into (6) will result in

$$
\begin{gathered}
I_{A}=-\frac{2}{\sqrt{3}} \frac{N_{2}}{N_{1}} I_{m}, \\
I_{B}=\frac{1}{\sqrt{3}} \frac{N_{2}}{N_{1}} I_{m}+\frac{N_{2}}{N_{1}} I_{t}, \\
I_{C}=\frac{1}{\sqrt{3}} \frac{N_{2}}{N_{1}} I_{m}-\frac{N_{2}}{N_{1}} I_{t} .
\end{gathered}
$$

Furthermore, the relation of voltages and currents at the secondary side can be expressed as

$$
I_{m}=Y_{m} V_{m}, \quad I_{t}=Y_{t} V_{t},
$$




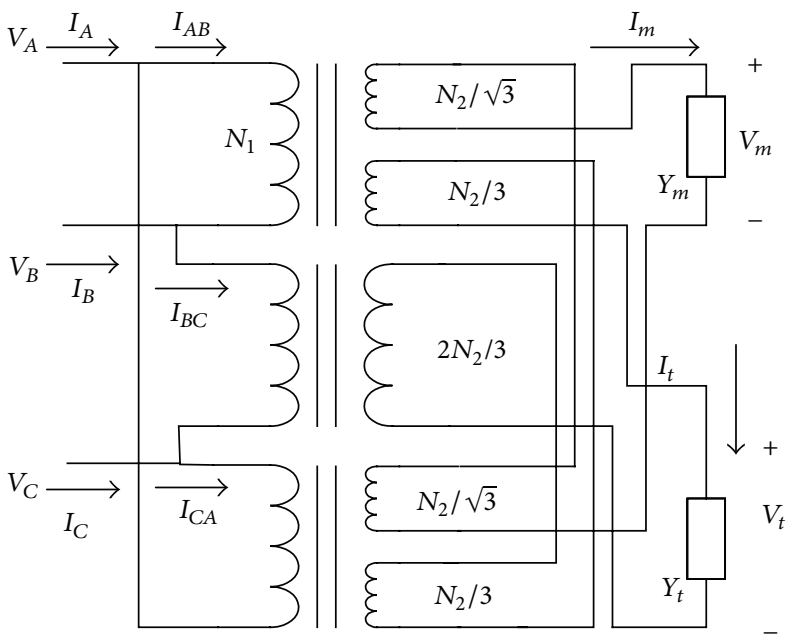

Figure 1: The Le-Blanc transformer connection diagram.
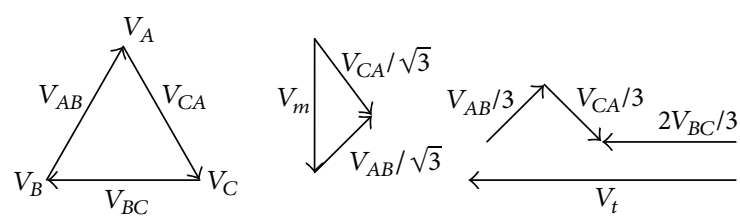

Figure 2: The Le-Blanc transformer voltage vector diagram.

where $Y_{m}$ and $Y_{t}$ are the admittances of the loading at secondary side. The primary line currents are thus obtained by substituting (9) into (8) as follows:

$$
\begin{gathered}
I_{A}=-\frac{2}{\sqrt{3}} \frac{N_{2}}{N_{1}} Y_{m} V_{m}, \\
I_{B}=\frac{1}{\sqrt{3}} \frac{N_{2}}{N_{1}} Y_{m} V_{m}+\frac{N_{2}}{N_{1}} Y_{t} V_{t}, \\
I_{C}=\frac{1}{\sqrt{3}} \frac{N_{2}}{N_{1}} Y_{m} V_{m}-\frac{N_{2}}{N_{1}} Y_{t} V_{t} .
\end{gathered}
$$

It is found that the sum of the primary line currents must be zero, which keeps three-phase balanced, regardless of the load at the secondary side.

\section{Distribution System and LRT Modeling}

Figure 3 shows the equivalent model of a multigrounded four-wire distribution system by the ATP software. The $69 \mathrm{kV}$ high voltage side of the distribution substation is simplified as an ideal three-phase source with a short circuit capacity of 1000 MVA. The test feeder is fed by a $69 \mathrm{kV} / 11.4 \mathrm{kV}, 25 \mathrm{MVA}$ power transformer sited in the distribution substation. The primary feeders and laterals are all overhead construction and their parameters are listed in Table 1 . In addition, there are 13 distribution transformers to serve the customers that are distributed along the test feeder. The active power and reactive power consumption of the customers in the feeder
TABLE 1: Line parameters.

\begin{tabular}{lcccc}
\hline \multirow{2}{*}{ Impedance } & \multicolumn{2}{c}{ Feeder } & \multicolumn{2}{c}{ Lateral } \\
& Phase & Neutral & Phase & Neutral \\
\hline Resistance $(\Omega / \mathrm{km})$ & 0.131 & 0.209 & 0.945 & 0.945 \\
Resistance $(\Omega / \mathrm{km})$ & 0.364 & 0.382 & 0.355 & 0.355 \\
\hline
\end{tabular}

are $4560 \mathrm{~kW}$ and $3420 \mathrm{kvar}$, respectively. Besides, a capacitor bank with a rating capacity of 2100 kvar is installed at the end terminal of the feeder. It is assumed that the test distribution system is operated under balanced condition. The grounding resistance of the neutral point of the substation power transformer and the grounding points along the neutral wire are assumed to be $1 \mathrm{ohm}$ and $25 \mathrm{ohm}$, respectively.

The electrical power of the tram must be fed from the TSS. The site of the TSS is $300 \mathrm{~m}$ from the distribution substation along the feeder. Figure 4 shows the TSS with a single-phase transformer to supply the tram. In Figure 5, the transformer is replaced with the proposed Le-Blanc transformer connection, which converts a three-phase power into two singlephase powers to supply the tram. The AC power voltage is further step down by the transformer installed at the tram and is rectified into DC power then. Finally, it is converted into controllable voltage and frequency AC power to drive the induction motors with a total capacity of $720 \mathrm{~kW}$ for the tram.

\section{Voltages and Unbalance Analysis}

This section is to explore the influence of unbalance, voltage drop, and the neutral line current variation on the threephase four-wire multi-grounding distribution feeder system with AC power supply to the tram.

5.1. Case 1: Original System. This case executes the relative analysis without considering the tram loading. First, the ATP software is applied to obtain the power system responses. 


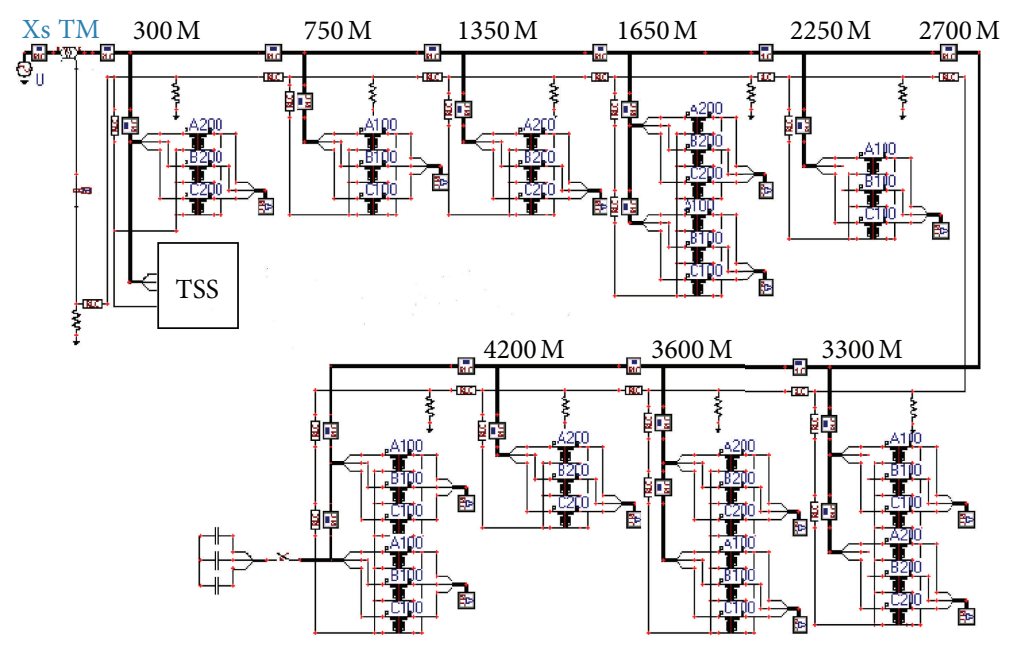

FIGURE 3: ATP modeling of the test distribution system.

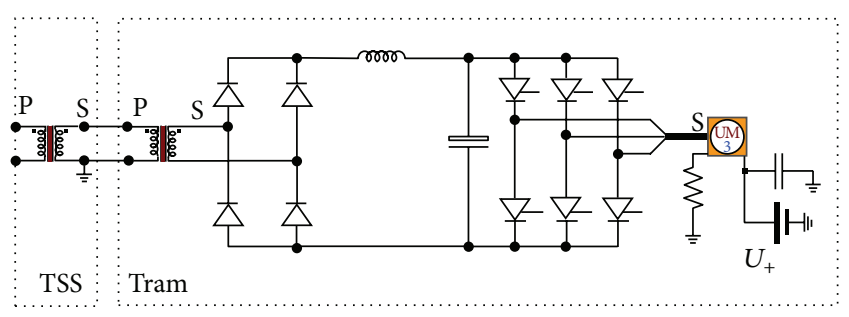

FIgURE 4: A TSS with the single-phase transformer connection.

For the original test feeder, the neutral line current is very close to zero as shown in Figure 6. It means that the original system is a balance system because all the load and lines are assumed to be three-phase balance. Figure 7 shows the threephase voltage magnitude at different sites of the feeder. The secondary side of the substation has the highest phase voltage of $6543 \mathrm{~V}$, which is about $0.994 \mathrm{pu}$. It is also observed that the lowest voltage of $6463 \mathrm{~V}$ occurred at the distance of $2700 \mathrm{~m}$ from the substation. It is acceptable for the utility because the voltage magnitudes at any feeder sites are higher $0.982 \mathrm{pu}$.

5.2. Case 2: TSS Using Single-Phase Transformer. In this case, the TSS supplies AC electric power to the tram through a singlephase transformer which is connected to the phase $\mathrm{C}$ of the utility grid as shown in Figure 4 . First, the ATP software is executed to obtain the power system responses by assuming that one tram is running. Figure 8 shows the three-phase voltage magnitude. The secondary side of the substation has the highest phase voltages of $6536 \mathrm{~V}, 6543 \mathrm{~V}$, and $6519 \mathrm{~V}$ for $A, B$, and $C$ phases, respectively. Relatively, the lowest voltages appear at the distance of $2700 \mathrm{~m}$ from the substation, which are $6424 \mathrm{~V}, 6434 \mathrm{~V}$, and $6433 \mathrm{~V}$. It is acceptable for the utility because the voltage magnitudes at any feeder sites are higher than 0.976 pu. Figures 9 and 10 show the instantaneous three-phase voltage and current at the secondary side of the substation. It is observed that the current on phase $C$ is larger than that on phases $A$ and $B$ due to a contribution of $720 \mathrm{~kW}$ tram loading. Figure 11 shows the neutral current flow through the substation transformer.

By applying the unbalance definition previously, the voltage unbalances are calculated as VUF $=0.65 \%, d_{2}=$ $0.47 \%$ and $d_{0}=0.22 \%$, while the current unbalances are obtained as IUF $=27.3 \%, m_{2}=15.7 \%$, and $m_{0}=11.6 \%$. Figures 12 and 13 show the voltage and current unbalances at the secondary side of the substation as the sites of the TSS change. When the TSS is located at $2250 \mathrm{~m}$ point, the voltage unbalances are calculated as VUF $=0.52 \%, d_{2}=0.27 \%$, and $d_{0}=0.18 \%$, and the current unbalances are obtained as IUF $=23.7 \%, m_{2}=13.6 \%$, and $m_{0}=9.5 \%$. Likewise, as the TSS is located at $4200 \mathrm{~m}$ point, the voltage unbalances are calculated as VUF $=0.4 \%, d_{2}=0.19 \%$, and $d_{0}=0.13 \%$, and the current unbalances are obtained as IUF $=18.6 \%$, $m_{2}=10.1 \%$, and $m_{0}=7.2 \%$. Figure 14 shows the neutral current flow through the substation transformer as the TSS is located at different points. The neutral currents are $132 \mathrm{~A}$, $51.7 \mathrm{~A}$, and $26 \mathrm{~A}$ as TSS is located at $300 \mathrm{~m}, 2250 \mathrm{~m}$, and $4200 \mathrm{~m}$ points, respectively. Obviously, all the voltage and current unbalances and the neutral current vary as the TSS is located at different points. The further the TSS is located away from the secondary side of the substation, the smaller the values become.

5.3. Case 3: TSS Using the Le-Blanc Transformer. To reduce the unbalance problem resulting from the TSS with a singlephase transformer connection, the Le-Blanc transformer connection is adopted in the TSS as shown in Figure 5. Figure 15 shows the three-phase voltages at different buses along the feeder. At the secondary side of the substation, the three-phase voltages of $V_{A}, V_{B}$, and $V_{C}$ are $6522 \mathrm{~V}, 6512 \mathrm{~V}$, and $6521 \mathrm{~V}$, respectively. These values decrease to $6435 \mathrm{~V}$, $6425 \mathrm{~V}$, and $6434 \mathrm{~V}$ at the distance around $2700 \mathrm{~m}$ from the substation. Figures 16 and 17 show the instantaneous three-phase voltages and currents at the secondary side of the substation. The neutral line current flows through the substation transformer, which is very small, as shown in 


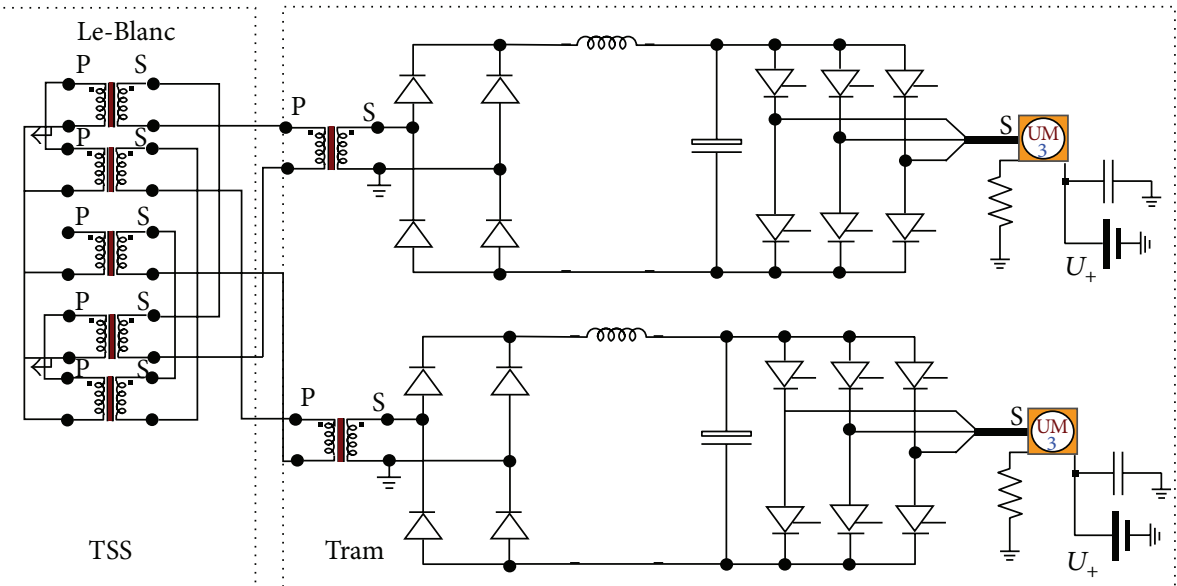

Figure 5: A TSS with the Le-Blanc transformer connection.

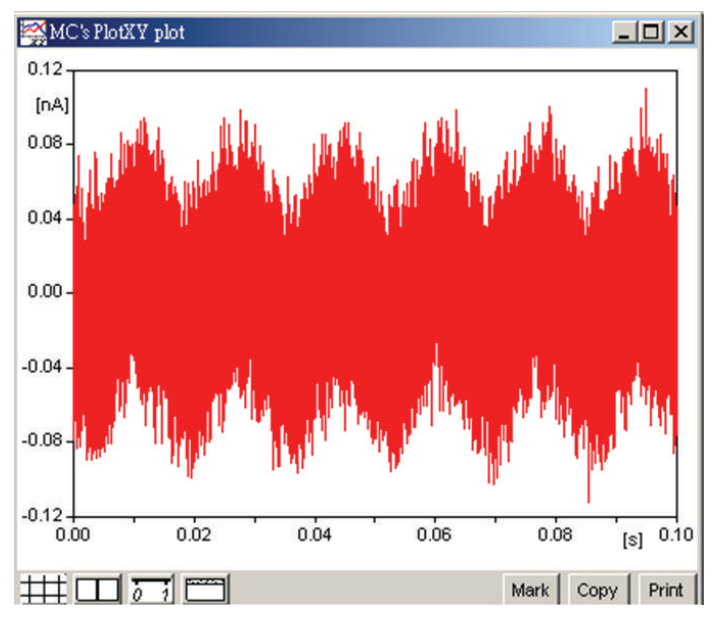

FIGURE 6: Instantaneous neutral line current at substation terminal for Case 1 .

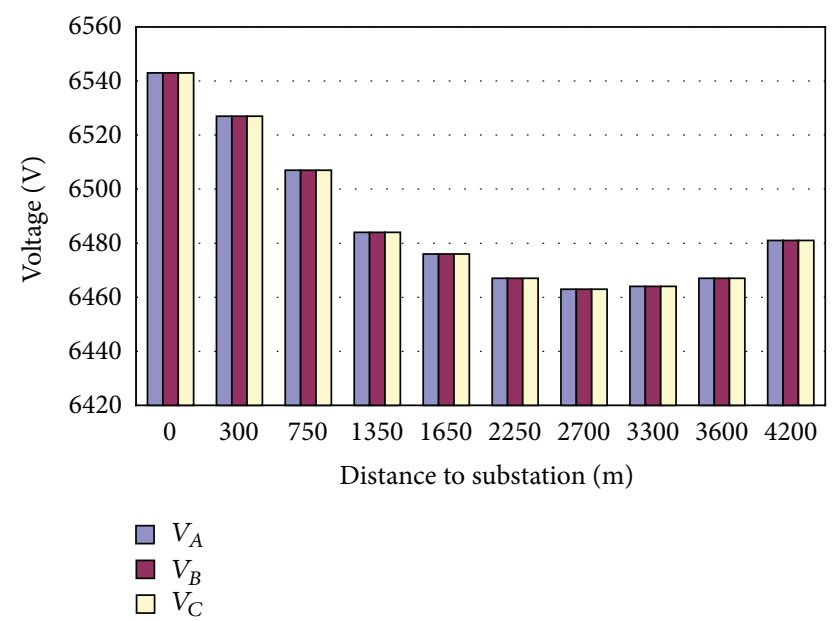

FIGURE 7: Three-phase voltage magnitudes at different feeder sites for Case 1 .

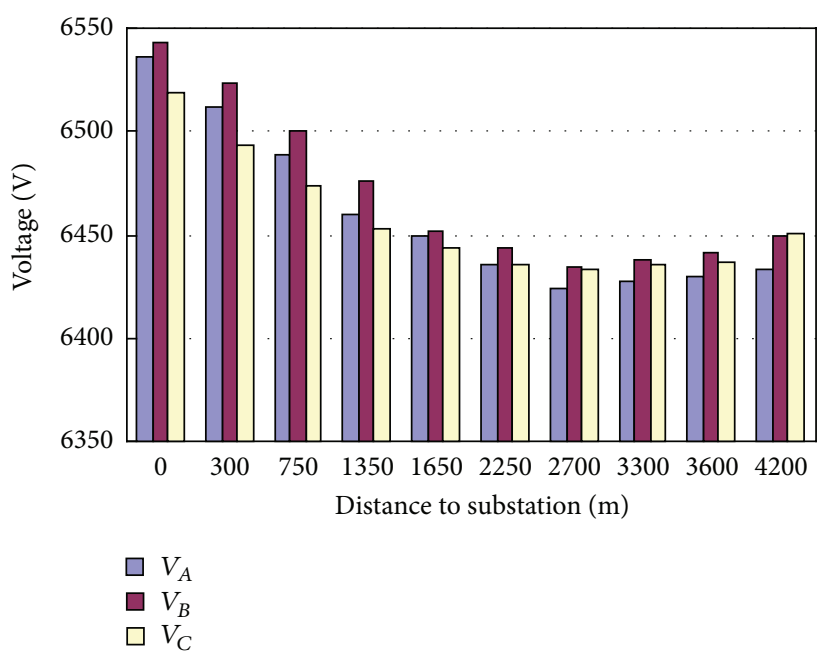

FIGURE 8: Three-phase voltage magnitudes at different feeder sites for Case 2.

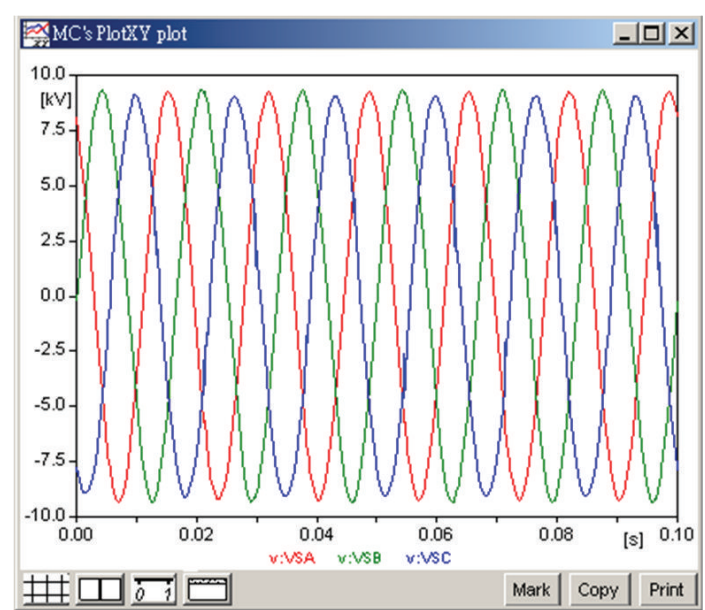

FIGURE 9: Instantaneous three-phase voltages at substation terminal for Case 2. 


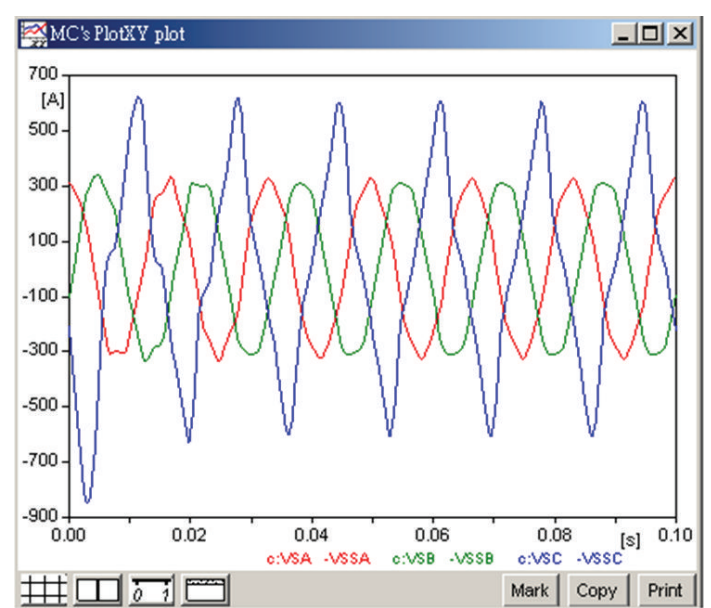

FIGURE 10: Instantaneous three-phase currents at substation terminal for Case 2.

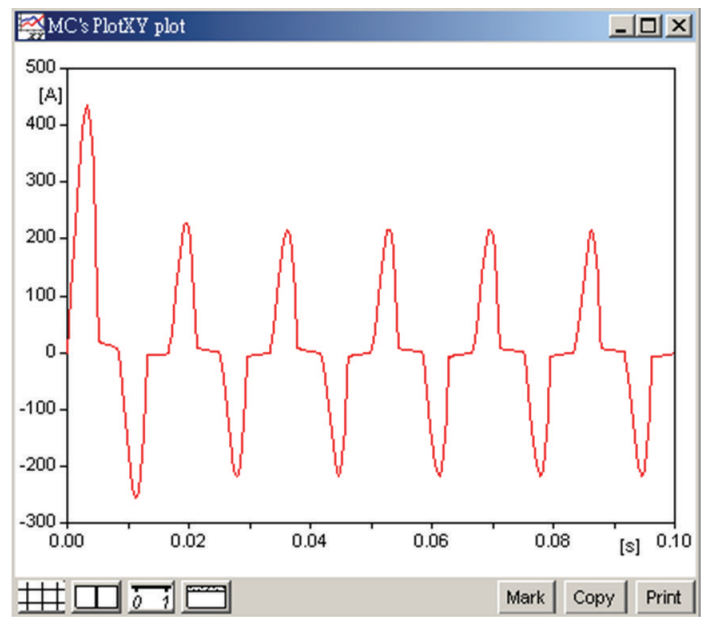

FIGURE 11: Instantaneous neutral line current at substation terminal for Case 2 .

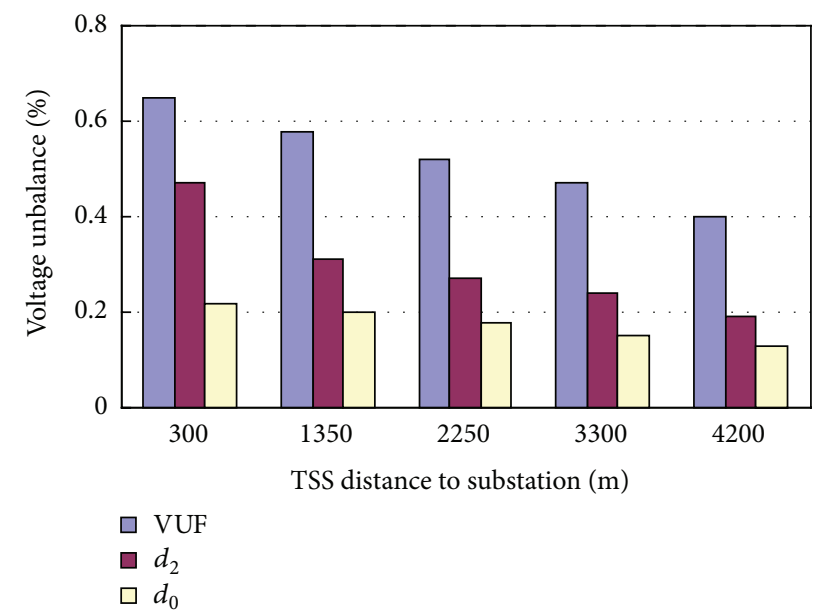

FIGURE 12: Voltage unbalance at substation terminal with different TSS sites for Case 2.

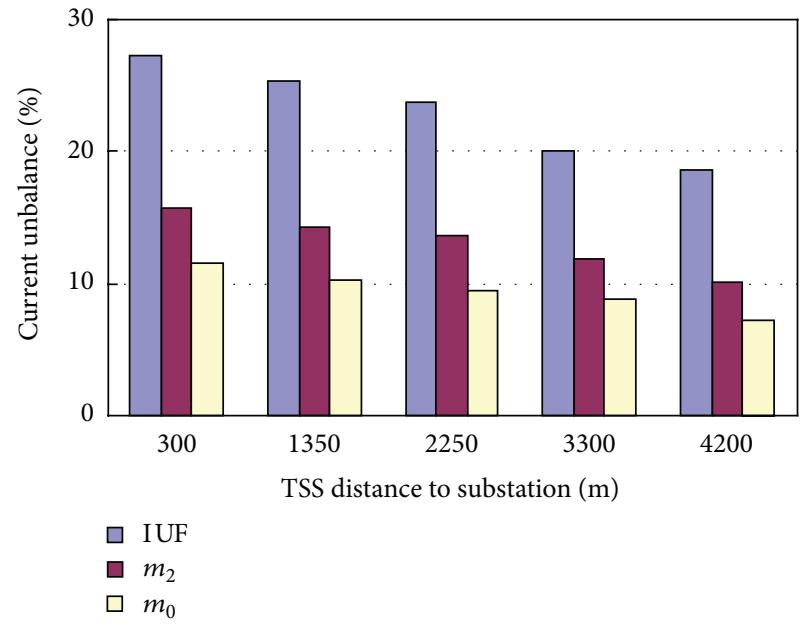

FIGURE 13: Current unbalance at substation terminal with different TSS sites for Case 2 .

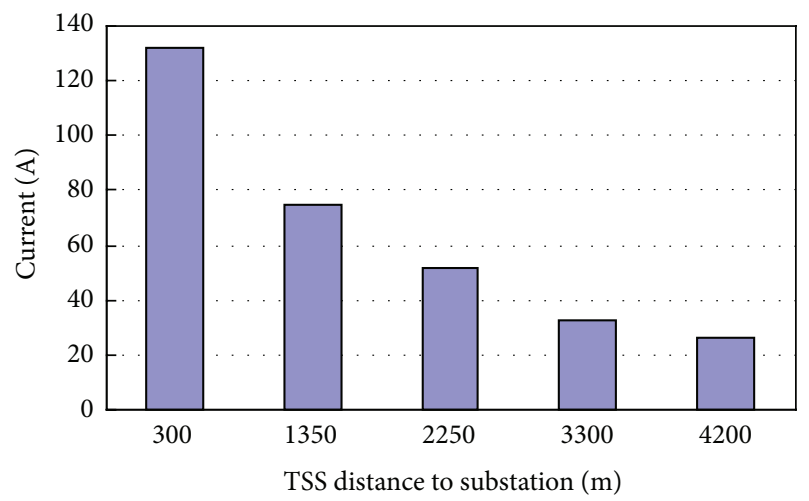

FIGURE 14: Neutral current at substation terminal with different TSS sites for Case 2 .

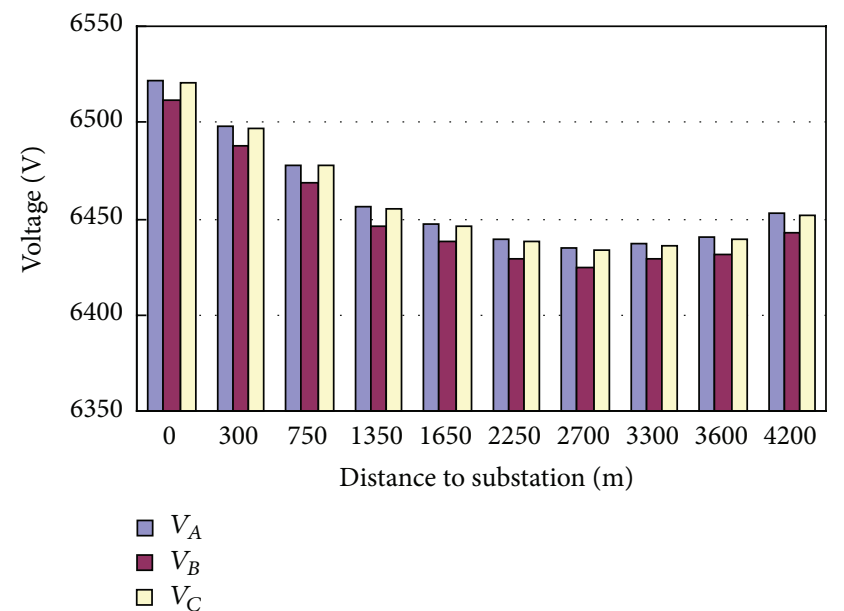

FIGURE 15: Three-phase voltage magnitudes at different feeder sites for Case 3. 


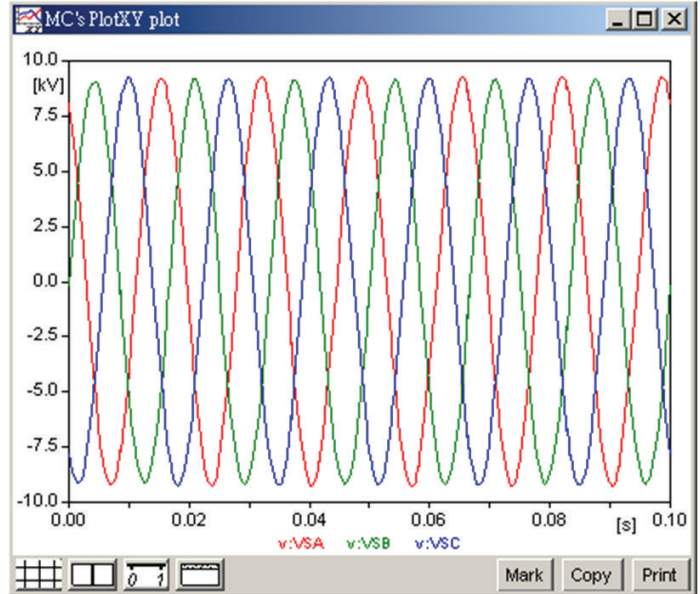

FIGURE 16: Instantaneous three-phase voltages at substation terminal for Case 3.

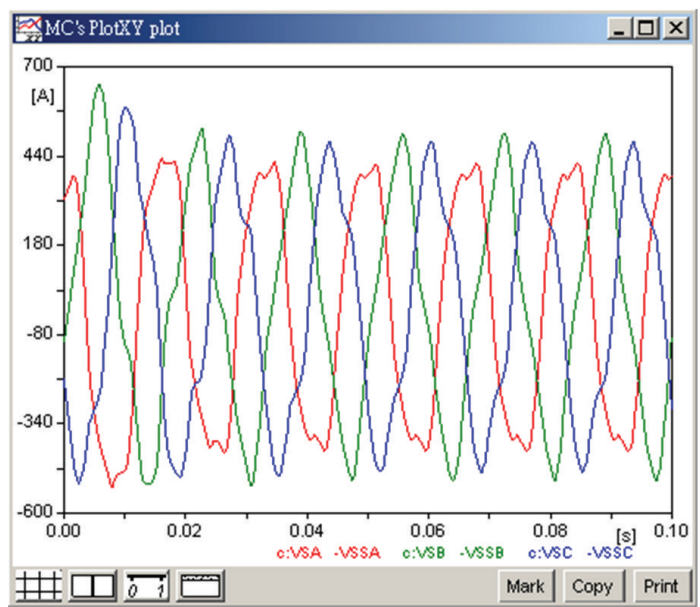

FIGURE 17: Instantaneous three-phase currents at substation terminal for Case 3.

Figure 18. In this case, the voltage unbalances are calculated as VUF $=0.059 \%, d_{2}=0.0018 \%$, and $d_{0}=0.0016 \%$, and the current unbalances are obtained as IUF $=0.06 \%$, $m_{2}=0.0105 \%$, and $m_{0}=0.0127 \%$ at the secondary side of the substation.

Figures 19 and 20 depict the voltage and current unbalance as the TSS is in different locations away from the secondary side of the substation. The voltage unbalances are calculated as VUF $=0.035 \%, d_{2}=0.0013 \%$, and $d_{0}=$ $0.001 \%$ when the TSS is located at a distance of $2250 \mathrm{~m}$ from the secondary side of the substation, and the current unbalances are obtained as IUF $=0.0043 \%, m_{2}=0.0092 \%$, and $m_{0}=0.01 \%$. The voltage unbalances are calculated as VUF $=0.019 \%, d_{2}=0.0008 \%$, and $d_{0}=0.007 \%$ as the TSS is installed at the $4200 \mathrm{~m}$ point away from the secondary side of the substation, and the current unbalances are determined as IUF $=0.0027 \%, m_{2}=0.0074 \%$, and $m_{0}=0.007 \%$. Figure 21 illustrates the neutral line currents for different locations of the TSS. The neutral line currents are $73.5 \mathrm{~mA}, 26.4 \mathrm{~mA}$,

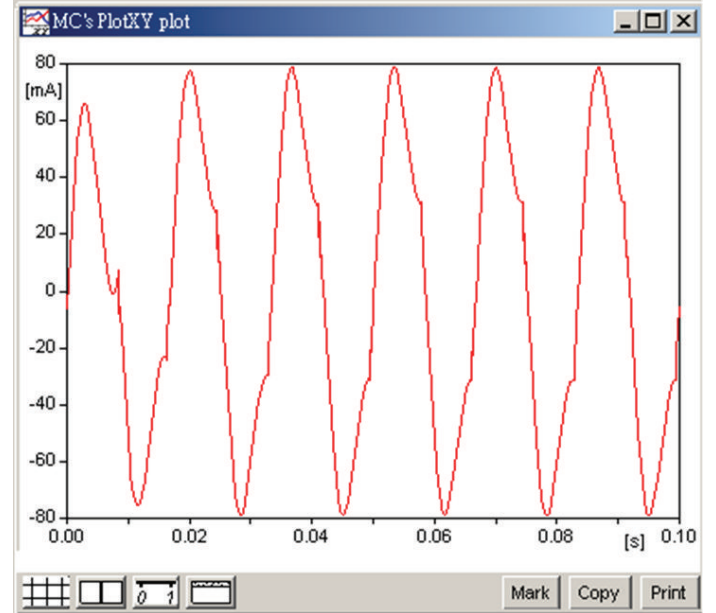

FIGURE 18: Instantaneous neutral line current at substation terminal for Case 3.

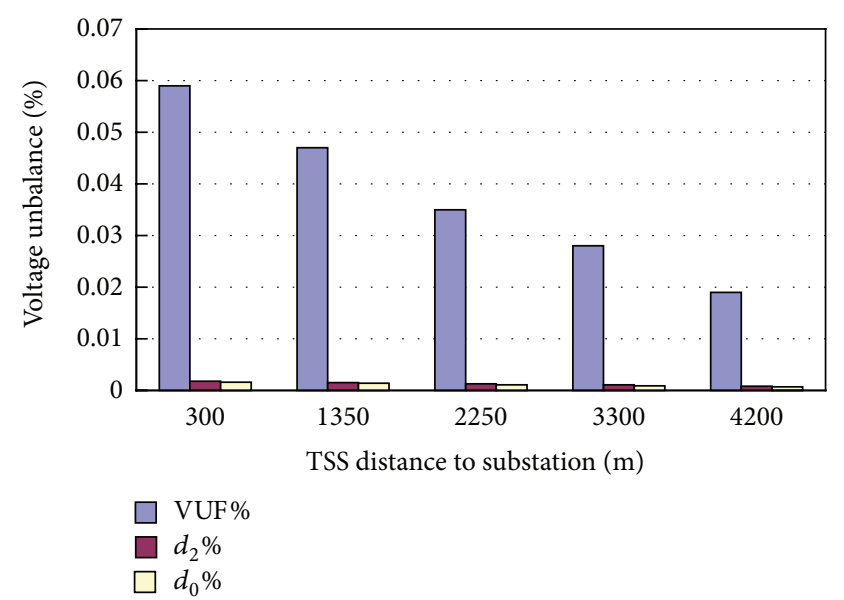

FIGURE 19: Voltage unbalance at substation terminal with different TSS sites for Case 3 .

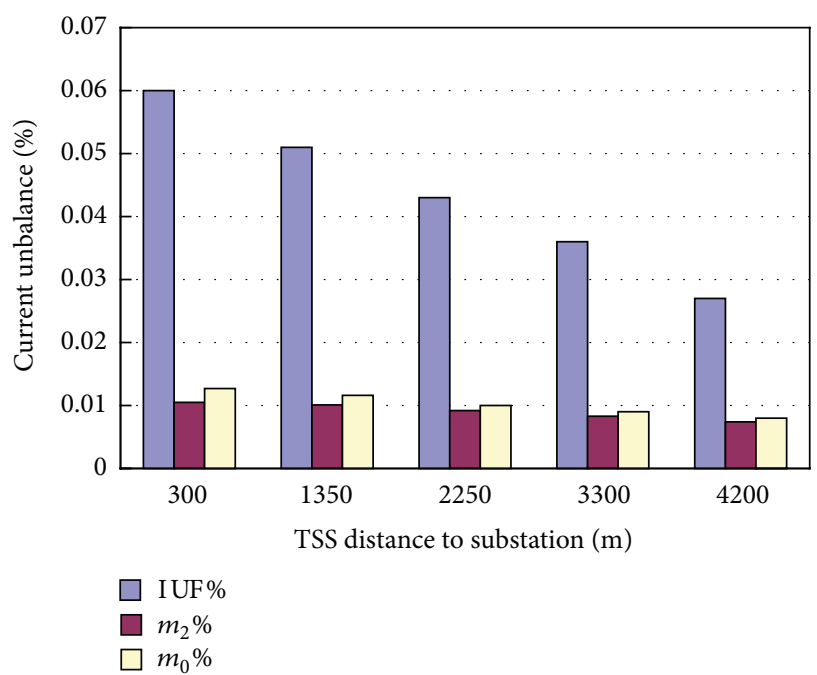

Figure 20: Current unbalance at substation terminal with different TSS sites for Case 3 . 


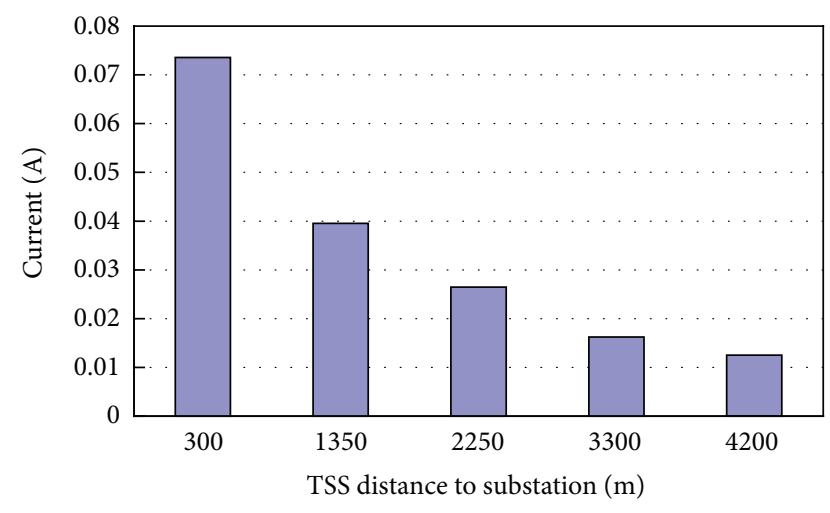

FIGURE 21: Neutral current at substation terminal with different TSS sites for Case 3.

and $12.5 \mathrm{~mA}$ when the TSS is located at $300 \mathrm{~m}, 2250 \mathrm{~m}$, and $4200 \mathrm{~m}$ points, respectively.

\section{Conclusions}

For the original test system, it is a three-phase balance system. However, the neutral line current flowing through the substation transformer is increased to $132 \mathrm{~A}$ when the TSS of the LRT adopts a single-phase transformer to supply the tram. In addition, the negative voltage and current sequence unbalances at the secondary side of the substation are obtained as $0.47 \%$ and $15.7 \%$, respectively. To improve the poor power quality phenomenon, the TSS with the proposed Le-Blanc connection transformer is then used. It is found that the neutral line current flowing through the transformer and the negative voltage sequence unbalance decreases to the values of $0.074 \mathrm{~A}$ and $0.002 \%$, respectively. It is concluded that the proposed TSS design has a significant effect on threephase unbalances reduction for the distribution system with an LRT loading.

\section{Acknowledgment}

This work is supported by the NSC of Taiwan (NSC 102-3113P-214-001).

\section{References}

[1] P. Neroth, "Waiting for nowait-engineering transport," Engineering and Technology, vol. 4, no. 10, pp. 28-31, 2009.

[2] L. Li, H. Zhang, X. Wang, W. Lu, and Z. Mu, "Urban transit coordination using an artificial transportation system," Proceedings of the IEEE Transactions on Intelligent Transportation Systems, vol. 12, no. 2, pp. 374-383, 2011.

[3] J. Fishelson, D. Freckleton, and K. Heaslip, "Evaluation of automated electric transportation deployment strategies: integrated against isolated," IET Intelligent Transport Systems, vol. 7, no. 3, pp. 337-344, 2013.

[4] Z. Shu, S. Xie, K. Lu et al., "Digital detection, control, and distribution system for co-phase traction power supply application," Proceedings of the IEEE Transactions on Industrial Electronics, vol. 60, no. 5, pp. 1831-1839, 2013.
[5] P. E. Sutherland, M. Waclawiak, and M. F. McGranaghan, "System impacts evaluation of a single-phase traction load on a $115-\mathrm{kV}$ transmission system," Proceedings of the IEEE Transactions on Power Delivery, vol. 21, no. 2, pp. 837-844, 2006.

[6] T. H. Chen and W. C. Yang, ", "Analysis of multi-grounded fourwire distribution systems considering the neutral grounding," IEEE Transactions on Power Delivery, vol. 16, no. 4, pp. 710-7717, 2001.

[7] ATP Draw version 1.0 Users Manual, SINTEF TR A4790, 1998.

[8] IEEE PES Transmission and Distribution Committee, "IEEE recommended practice for monitoring electric power quality," IEEE Std 1159, 2009.

[9] B.-K. Chen and B.-S. Guo, "Three phase models of specially connected transformers," IEEE Transactions on Power Delivery, vol. 11, no. 1, pp. 323-330, 1996. 


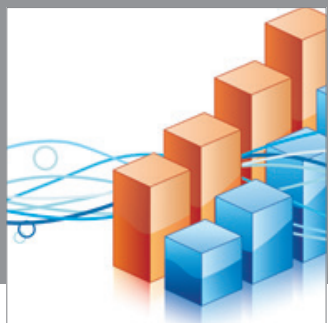

Advances in

Operations Research

mansans

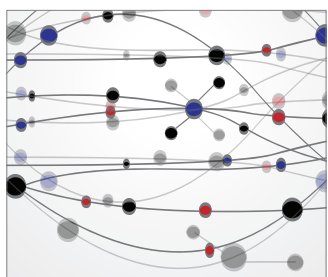

The Scientific World Journal
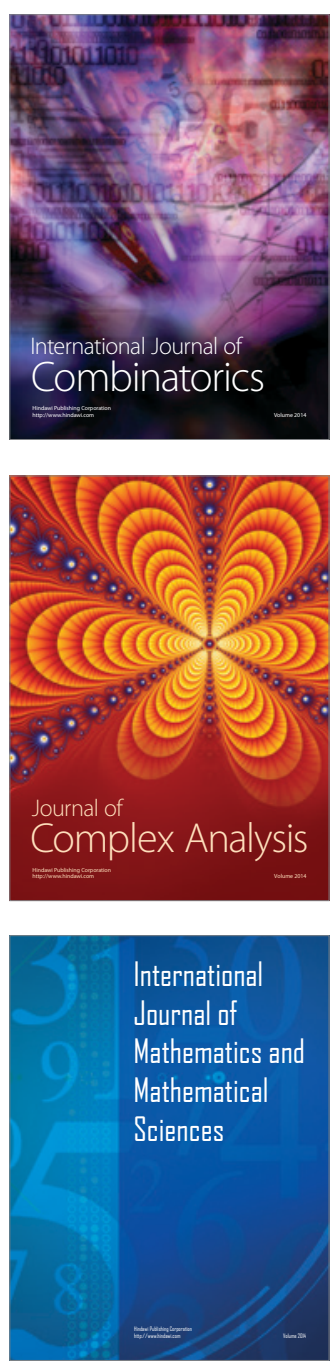
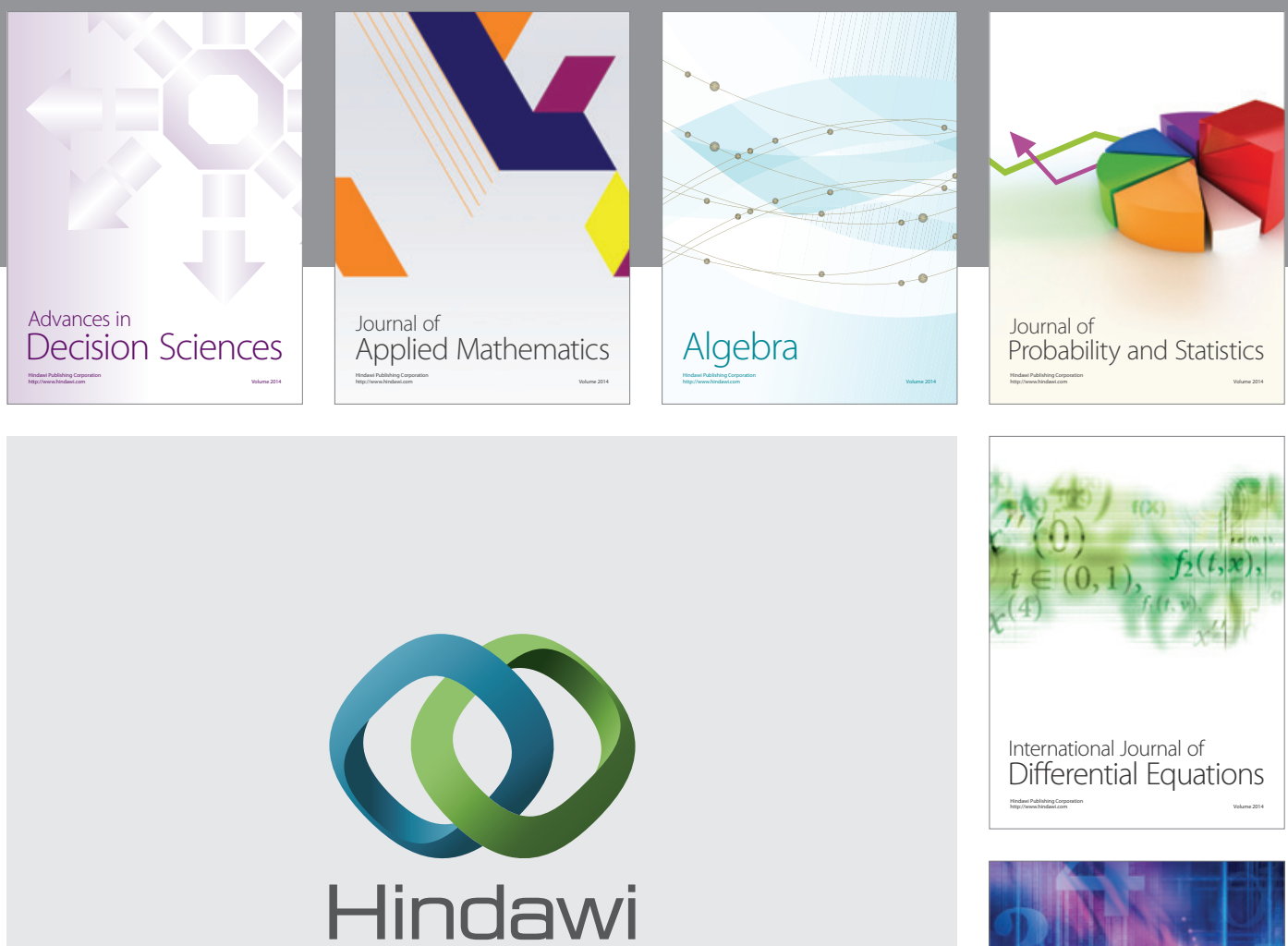

Submit your manuscripts at http://www.hindawi.com
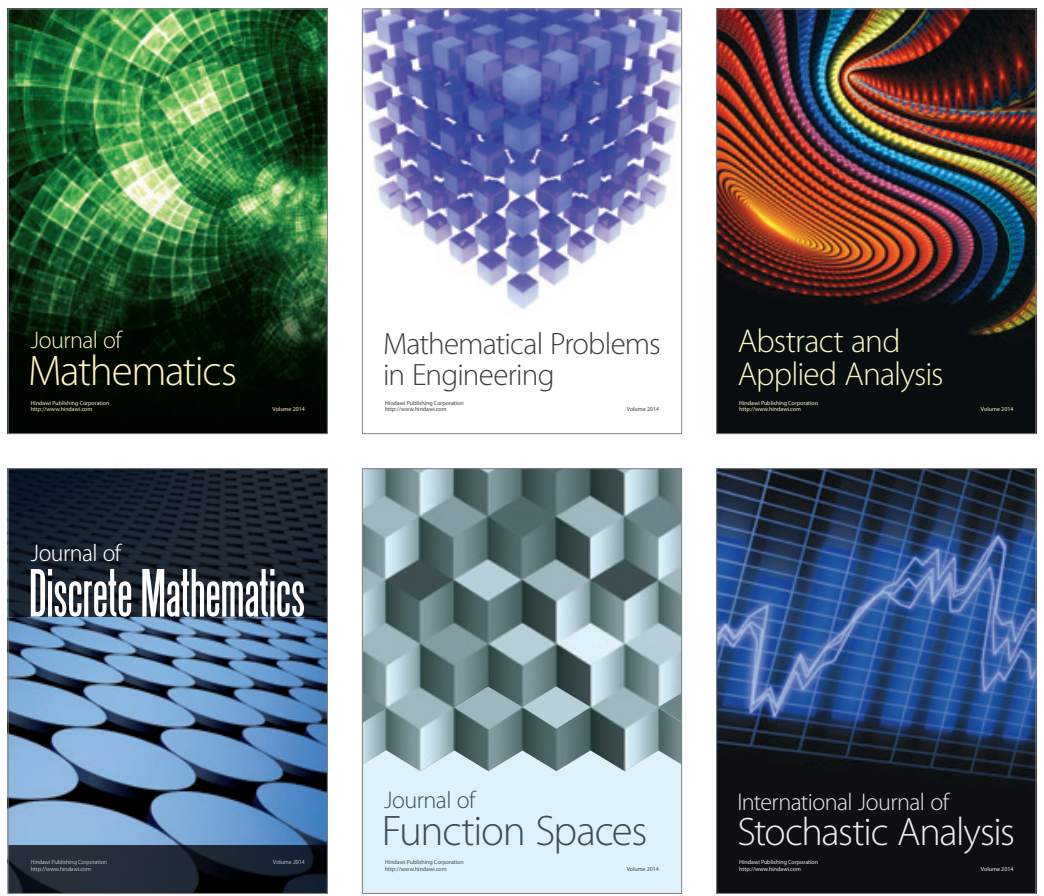

Journal of

Function Spaces

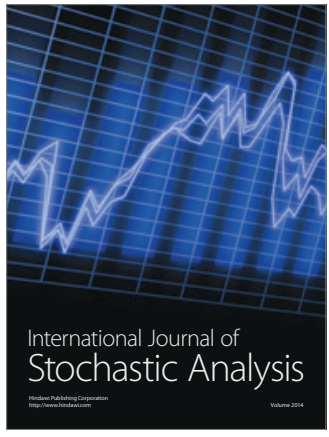

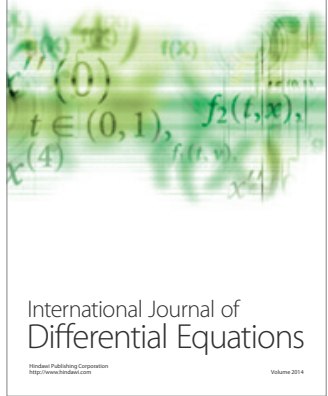
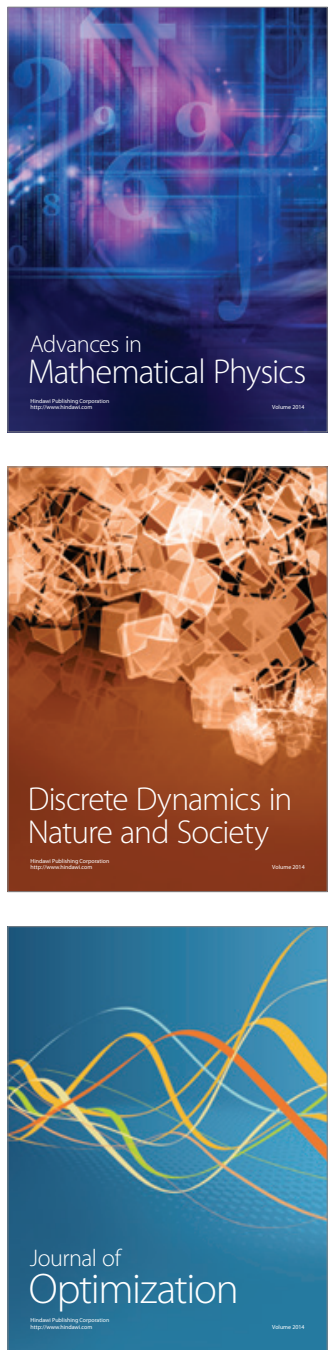